Review Article

\section{Timing of cardiac surgery and other intervention among children with congenital heart disease: A review article}

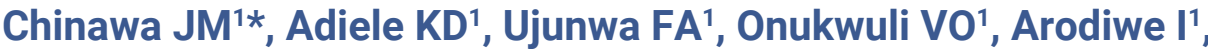

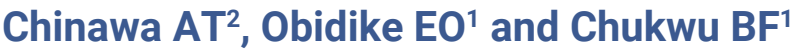 \\ 'Department of Paediatrics, College of Medicine, University of Nigeria Enugu Campus, Nigeria \\ ${ }^{2}$ Consultant, Community Physician \& Lecturer, Enugu State University Teaching Hospital, Enugu \\ State, Nigeria
}

\section{Abstract}

Background: Early diagnosis and improved facilities are necessary for determining the optimal timing of surgery and other interventions in children with congenital heart diseases in Nigeria. This is because late presentation, late diagnosis and delayed surgery can lead to mortality and affect the quality of life among these children.

Objectives: This review article is aimed at enumerating the timing of cardiac surgeries and other interventions and to seek if there is any factor associated with the timing of cardiac surgery.

Methods: A search on PubMed database, World Health Organization libraries, Google scholar, TRIP database, and reference lists of selected articles on timing of cardiac surgery in children was done. The Cochrane Database of Systematic Reviews was also searched. We noted few data from African setting. Key words such as timing of cardiac surgery; children, congenital heart defect were used.

Conclusion: Appropriate timing for cardiac surgery in children with congenital heart disease is very important as late surgical intervention could result in several morbidities and mortality.

\section{More Information}

*Address for Correspondence: Chinawa JM, Associate Professor, Pediatric Cardiology Firm Department of Paediatrics, College of Medicine, University of Nigeria Enugu Campus. Enugu, Nigeria. PMB 40001, Enugu, Nigeria, Tel: +234 803722 1864;

Email: maduabuchichinawa@yahoo.com; josephat.chinawa@unn.edu.ng

\section{Submitted: 25 July 2019 \\ Approved: 08 August 2019 \\ Published: 09 August 2019}

How to cite this article: Chinawa JM, Adiele KD, Ujunwa FA, Onukwuli VO, Arodiwe I, et al. Timing of cardiac surgery and other intervention among children with congenital heart disease: $\mathrm{A}$ review article. J Cardiol Cardiovasc Med. 2019; 4. 094-099.

\section{DOI: 10.29328/journal.jccm.1001047}

Copyright: (c) 2019 Chinawa JM, et al. This is an open access article distributed under the Creative Commons Attribution License, which permits unrestricted use, distribution, and reproduction in any medium, provided the original work is properly cited

Keywords: Timing of cardiac surgery; Children; Congenital heart defect

Check for updates

\section{Introduction}

Congenital heart disease is becoming a common cause of congenital abnormalities in our locale [1]. There is also a dramatic increase of the prevalence of congenital heart disease (CHD) which has risen from 4 to 5 per 1,000 live births among older studies to 12 to 14 per 1,000 live births, reported in the recent literature [2]. In the foregoing therefore, the diagnosis and treatment for congenital cardiac disease has also undergone remarkable progress over the last 6 decades [3]. Accurate timing and intervention significantly improves quality of life, prevents complications and reduces the morbidity and mortality associated with these defects. Worldwide, CHD are the main cardiac anomaly found in children and constitute one of the major causes of infant mortality, particularly in developing countries [4].

The indications and timing of intervention among children with congenital heart disease is decided by the severity and type of the lesion. For instance, balloon pulmonary valvuloplasty is the treatment of choice for valvar pulmonary stenosis and surgery must be done when the peak-to-peak systolic pressure gradient is more than $50 \mathrm{mmHg}$ across the pulmonary valve [5]. For aortic valve stenosis, balloon aortic valvuloplasty appears to be the first therapeutic procedure of choice with intervention feasible when peak-to-peak systolic pressure gradient across the aortic valve in excess of $70 \mathrm{mmHg}$ irrespective of the symptoms or a gradient more than and equal to $50 \mathrm{mmHg}$ with either symptoms or electrocardiographic ST-T wave changes indicative of myocardial perfusion abnormality [6]. The indications for intervention in coarctation of the aorta are significant hypertension and/or congestive heart failure along with a pressure gradient in excess of 20 mmHg across the coarctation [7]. In addition, it is important to remember that the defect once detected should be corrected whether by surgery or by nonsurgical methods as appropriate before ventricular dysfunction, pulmonary vascular change and other complications ensue. 
It is important to note that once ventricular dysfunction, pulmonary vascular change set in, the surgery becomes high risk with an increased chance of postoperative complications and poorer long-term results. Many of these cases may even become inoperable, if timely intervention is not done. Every cardiologist or cardiac surgeon must strive to get a complete diagnosis on a child suspected of having heart disease as soon as possible even if that requires referral to a higher centre. This review article is aimed at determining the timing of cardiac surgeries and other intervention in children with congenital heart disease and to seek if there is any factor associated with timing of cardiac surgery.

\section{Methods}

A search on PubMed database, World Health Organization libraries, Google scholar, TRIP database, and reference lists of selected articles on timing of cardiac surgery in children were done. The Cochrane Database of Systematic Reviews was also searched. Some studies were selected that included 2,027 children with congenital heart disease.

\section{Results}

In a study done in University of Nigeria Teaching hospital Enugu, Eighty-eight patients, consisting of $59.09 \%$ females and $40.91 \%$ males with cardiac anomalies presented to the facility over a period of 4 years. The mean age for cardiac surgical closure was 4.4 (4.1) years with minimum and maximum age of 2 months and 18 years respectively. Majority of the patients had surgery after their first birthday and substantial number after their 5th birthday. The gender of patients did not influence the time of surgery. The mean age at cardiac surgery in females was $4.0(0.5)$ years while that for males was 4.8 (0.7) years (Table 1$)$.

The time for the closure of cardiac defects was very late in developing countries as seen above, compared with that seen in Pakistan; another developing country, where the mean age at the time of surgery was $6.08 \pm 2.80$ months (Table 2).

In California, studies done between 1995-1996, 666 children were noted to have undergone ASD closure at a mean age of 5.1 years; median: 4.0 years, and 582 children with VSD closure had theirs at a mean age of 2.8 years; median: 1.1 years, while 394 children with TOF repair had repair at a mean age of 1.7 years; median: .9 years with 177 children who presented with AVC repair had their intervention at a mean age 1.1; median: .6 years (Table 3).

They noted that Asians tended to be older at surgery for all types of cardiac defects yet gender or race were noted not to have any effect on age at surgical closure of congenital heart defects. They however noted an association between the place of domicile and age at operation especially for ASD and TOF with no attendant link between distance to surgical centre and age at operation. It was seen that among 460-
467 live births to Massachusetts residents between 2004 and 2009, were among 916 children with congenital heart disease, 126 (13.8\%) had delayed diagnosis. Rates of prenatal CCHD diagnosis increased from $44.9 \%$ in 2004 to $63.8 \%$ in 2009, whereas rates of delayed diagnosis decreased from $17.1 \%$ to $10.6 \%$ over the same time period. Delayed diagnosis was associated with delivery outside a tertiary hospital and isolated congenital cardiac defect (Figure 1).

\section{Brief discussion of results on some studies as regards timing of cardiac surgery}

Accurate timing and intervention in children with congenital heart disease (CHD) significantly improves quality of life, prevents complications and reduces the morbidity and mortality associated with these defects. Worldwide, CHD are the main heart diseases found in children and constitute one of the major causes of infant mortality, particularly in developing countries. In fact, nine out of 10 new-borns with CHD will live in a developing country where cardiac care is suboptimal or unavailable entirely. Seventy percent of those infants in a developing nation will require medical or surgical intervention within their first year of life, and $30 \%$ of those children will die without treatment in that first year.

\begin{tabular}{|c|c|c|}
\hline Table 1: Age at surgical closure of cardiac anomaly. (UNTH ENUGU) & $\mathrm{n}=88$. \\
\hline Age at Surgery & Frequency & $\%$ \\
\hline$\leq 1$ & 14 & 15.9 \\
\hline$>1-5$ & 47 & 53.4 \\
\hline$>5$ & 27 & 30.7 \\
\hline Total & 88 & 100 \\
\hline
\end{tabular}

Table 2: Age at surgery of cardiac in Pakistan $n=120$ [8].

\begin{tabular}{|c|c|c|}
\hline Age at Surgery & Frequency & $\%$ \\
\hline $6.08 \pm 2.80$ Months & 51 & 42.5 \\
\hline $37.10 \pm 19.94$ Months & 69 & 57.5 \\
\hline$>5$ & 0 & 0 \\
\hline Total & 120 & 100 \\
\hline
\end{tabular}

Table 3: Age of closure in Massachusetts [9].

\begin{tabular}{|c|c|}
\hline Defect Age at Closure (Mean) & Frequency \\
\hline ASD 5.1 years; median: 4.0 years & 666 \\
\hline VSD 2.8 years; median: 1.1 years & 582 \\
\hline TOF 1.7; median: .9 years & 394 \\
\hline AVC 1.1; median: .6 years & 177 \\
\hline
\end{tabular}

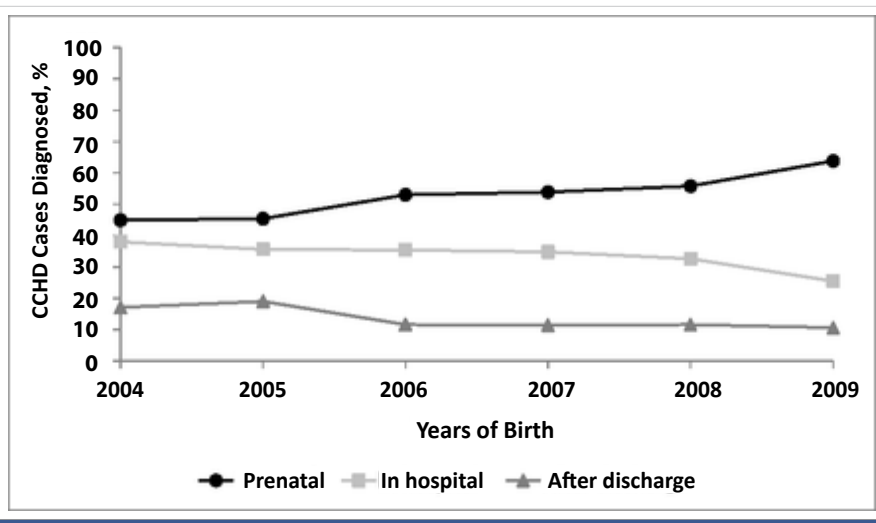

Figure 1: Trends in timing of diagnosis by birth year are shown in Massachusetts [10]. 
In developing countries like Nigeria, most surgical intervention for all cardiac lesions takes place between 1 and 5 year of age. In a study done in University of Nigeria Teaching hospital Enugu, it is noted that the mean age for cardiac surgical closure was 4.4 (4.1) years with minimum and maximum age of 2 months and 18 years respectively. It was also noted that gender of patients did not influence the time of surgery. The time for the closure of cardiac defects was very late in developing countries as seen above, compared with that seen in Pakistan another developing country, where the mean age at the time of surgery was $6.08 \pm 2.80$ months [8].

In California, studies done between 1995-1996, 666 children were noted to have undergone closure at earlier age. They noted that Asians tended to be older at surgery for all types of cardiac defects yet gender or race were noted not to have any effect on age at surgical closure of congenital heart defects. They however noted an association between the place of domicile and age at surgical closure [9]. In a study in Massachusetts, it was noted that among 916 children with congenital heart disease, 126 (13.8\%) had delayed diagnosis. Delayed diagnosis was associated with delivery outside a tertiary hospital and isolated congenital cardiac defect [10]. The study above is similar to what is obtainable in the western world. For instance, Roheena, et al. [11] noted in their study that the earliest time of surgical intervention for their subjects is less than 1 year [11]. The reason for this late surgical intervention in this part of the world could be explained by the fact that surgical closure or any intervention for cardiac lesions is very costly and most people can't afford it due to the harsh economic situations in the country. Moreover, surgery in this region is not done routinely due to lack of facilities and enabling environment.

\section{Review on time of repair of various congenital heart disease}

Time for surgical closure of Atrio septal defect (ASD): Spontaneous closure is rare if defect is more than $8 \mathrm{~mm}$ at birth and rare after age 2 years. Very rarely an ASD can enlarge on follow up. It is therefore, important to note that ideal time of closure should be about three months when there is a fall of pulmonary vascular resistance. For ASDs, Indication for closure includes ASD associated with right ventricular volume overload and the Ideal age of closure in asymptomatic child is usually 2-4 years and 4-5 years for sinus venosus [12].

Timing of surgical repair of atrio-ventricular-septal defect (AVSD): Timing of intervention varies, depending on the type of congenital heart defect. For instance, in complete atrio-ventricular-septal defect (AVSD) with uncontrolled congestive heart failure, surgery is usually done as soon as possible after optimization [9-13]. Furthermore, incomplete Atrio ventricular septal (AVSD) with controlled heart failure, complete surgical repair by 3-6 months of age is advocated and pulmonary artery banding may be necessary if risk of cardiopulmonary bypass is considered high. In Partial AVSD, surgery at about 2-3 years of age is advocated, however, associated significant AV regurgitation may necessitate early surgical intervention. Pulmonary artery banding should be done if risk of cardiopulmonary bypass is considered high [1317]. Regrettably, in the developing country and sub-Saharan Africa, children with atrio-septal defects were maintained on anti-failure regimen with regular follow up until surgical intervention is possible. This makes some of them inoperable due to high pulmonary vascular resistance.

Time of closure of ventricular septal defect (VSD): In large (non-restrictive) VSD, where diameter of the defect is approximately equal to diameter of the aortic orifice, surgery should be done immediately. However, in children where right ventricular systolic pressure is systemic with high pulmonary vascular resistance, surgery may be impossible [18-22]. There have been general indications for surgical closure of VSD, which include patients at any age with large defects in whom clinical symptoms and failure to thrive cannot be controlled medically, infants between 6 and 12 months of age with large defects associated with pulmonary hypertension, children older than 24 months with a Qp: Qs ratio greater than 2 and children with a supra-cristal (doubly committed) VSD of any size (because of the high risk for aortic valve regurgitation) [20]. Contraindications to surgical closure of VSD include severe pulmonary vascular disease nonresponsive to pulmonary vasodilators.

Generally, in symptomatic infants with VSD, pulmonary vascular disease is usually prevented when surgery is performed within the 1st year of life except if there is evidence of shunt becoming restrictive [14-24]. For large VSD with uncontrolled congestive heart failure, closure should be done as soon as possible while in large VSD with severe pulmonary artery hypertension, closure should be done at 3-6 months of age. For moderate VSD where pulmonary artery systolic pressure is $50 \%-66 \%$ of systemic pressure, closure should be at 1-2 years of age or earlier if one episode of life threatening lower respiratory tract infection or failure to thrive ensues [18-24]. In the case of small sized VSD, with normal pulmonary artery pressure and left to right shunt $>1.5: 1$, it is important to institute closure by $2-4$ years [1419]. Small outlet VSD $(<3 \mathrm{~mm})$ without aortic valve prolapse should be on 1-2 yearly follow up to look for development of aortic valve prolapse. In addition, small outlet VSD with aortic valve prolapse without aortic regurgitation, should be closed by 2-3 years of age irrespective of the size and magnitude of left to right shunt $[25,26]$.

Small outlet VSD with any degree of aortic regurgitation (especially in supra cristal type) should be closed whenever aortic regurgitation is detected. While small peri-membranous VSD with aortic valve prolapse with no or mild aortic regurgitation should be reviewed with 1-2 yearly follow up to look for any increase in aortic regurgitation [25,26]. 
For situations like Small Peri-membranous VSD with aortic cusp prolapse with more than mild aortic regurgitation, surgery is done whenever aortic regurgitation is detected. However, for small VSD with one or more episodes of infective endocarditis, early VSD closure is recommended [25,26]. The mode of closure for VSDs is usually surgical closure, device closure should however be done in muscular VSD especially for children weighing more than $15 \mathrm{Kg}$. In addition, pulmonary artery banding is usually indicated for multiple (Swiss cheese) VSD in very large VSD with almost a single ventricle, in infants with low weight (less than $2 \mathrm{Kg}$ ) and associated co-morbidity like chest infection [18-25]. In countries where facilities for closure are not available, late closure is the norm and at times Eisenrger's complex could result from late surgical closure.

Time of closure of Patent Ductus Arteriosus (PDA): In children with a patent ductus arteriosus, spontaneous closure occurs up to 3 months of age though this rarely happens after 1week of age. However large PDAs are unlikely to close [27]. Cardiac Intervention is very necessary in a preterm baby if the baby is in heart failure (small PDAs may close spontaneously). Indomethacin or Ibuprofen can be given to close the duct if there were no contraindication. Surgical ligation can be done if the above drugs fail [28,29]. Timing of closure of Patent ductus arteriosus (PDA) varies, for instance large/ moderate PDA, with congestive heart failure and pulmonary artery hypertension, should be ligated or close with catheter as early as 3-6 months of age [28,29].

For moderate PDA without congestive heart failure, closure should be at 6 months- 1 year of age. If failure to thrive ensues, closure can be accomplished earlier [28-30]. Mode of closure of PDA could range from device closure, coils occlusion or surgical ligation children more than 6 months of age, surgical ligation should be done if less than 6 months of age while device/ coils is done in children less than 6 months of age. It is important to note that Indomethacin/ ibuprofen cannot be used in term babies [28-33].

Timing for coarctation of the aorta: For Timing for coarctation of the aorta, if there is left ventricular dysfunction / congestive heart failure or severe upper limb hypertension (for age), immediate intervention is advocated. In situations where there is normal left ventricular function and no congestive heart failure with mild upper limb hypertension, intervention could be beyond 3-6 months of age. If there is no hypertension, no heart failure and normal ventricular function, Intervention at 1-2 years of age is advised. Intervention is not indicated if doppler gradient across coarctation segment is less than $20 \mathrm{mmHg}$ with normal left ventricular function [28-33]. Balloon dilatation for coarctation or surgery can be considered for children more than 6 months of age. Surgical repair for infants less than 6 months of age can be done and this involves resection of the stenosed segment and reanastomosis. Balloon dilatation with stent deployment can be considered in children more than 10 years of age if required, especially in cases of re-coarctation and post-surgical repair [30-34].
Timing for pulmonary stenosis: Timing for pulmonary stenosis also depend on certain factors. For instance, in right ventricular dysfunction, immediate intervention (valvuloplasty) irrespective of gradient should be done. In case with normal right ventricular function, balloon dilatation if Doppler gradient (peak) of more than $60 \mathrm{mmHg}$. In neonates balloon dilatation is indicated if right ventricle dysfunction/ mild hypoplasia or hypoxia is present $[35,36]$.

Timing for intra cardiac repair of Teratology of fallot (TOF): In teratology of fallot (TOF), total correction should be at 1-2 years of age but if there is significant cyanosis $(\mathrm{SaO} 2<$ $70 \%$ ) or history of spells despite medical therapy especially plasma or saline phaeresis, then systemic to pulmonary artery shunt (Blalock Taussig shunt) should be done at less than 3 months, but if the child is more than 3 month, shunt or correction depending on anatomy and surgical centers' experience should be done [34-37].

Timing for repair of VSD with pulmonary atresia: For children with VSD with pulmonary atresia, repair should be at 3-4 years, if right ventricle to pulmonary artery conduit is required. Systemic to pulmonary artery shunt should be done if the child is symptomatic [34-36]. In TOF-like conditions where two ventricular repair is possible (DORV), timing of surgery also varies. For instance, for stable cases who are mildly cyanosed, repair at 1-2 years of age if conduit is not required while repair is at 3-4 years of age if conduit is required. Systemic to pulmonary shunt (Blalock-Taussig shunt) should be done if the child presents earlier with significant cyanosis (SaO2<70\%) [34-38].

Timing for repair of transposition of great arteries (TGA): For transposition of great arteries (TGA), timing of intervention depends on the integrity of the interventricular septum. In TGA with Intact interventricular septum, if the child is less than 3-4 weeks of age; Arterial switch operation should be done immediately. If the patient is more than 3-4 weeks of age at presentation; it is expedient to assess the left ventricle mass and possibility of regression by echocardiography $[37,39]$. If the left ventricle is regressed, Senning /Mustard operation should be done at 3-6 month. It is very important to point out here that rapid two stage arterial switch approach would depend on institutional practice $[37,38]$. For example, If the left ventricle is still functional, very early arterial switch operation should be carried out. In borderline left ventricle; Senning or Mustard; or arterial switch operation is indicated. Adequacy of left ventricle for arterial switch operation can be assessed by echocardiography in most cases. In cases where a child presents with TGA with ventricular septal defect; Arterial switch operation by 3 months of age is necessary [3840].

Several reasons have been propounded forlate presentation and surgical intervention especially in a resource poor country. This ranges from late presentation due to ignorance to low socioeconomic class, unavailability of adequate 
facilities, loss to follow-up despite proper diagnosis. Other reasons are refusal of surgery by some parents, unavailability of adequate manpower in the area of corrective heart surgery, some turbulent post-op cases and lack of proper coordination and synergy in all specialties involved in open heart surgery due to non- routine practice.

\section{Factors associated with timing of surgical closure}

Some authors have noted that gender or race had no effect on age at surgical closure of congenital heart defects. This was corroborated by Chang, et al. [38], who noted that although Asians tended to be older at surgery for all types of cardiac defects yet gender or race were noted not to have any effect on age at surgical closure of congenital heart defects. They however noted an association between the place of domicile and age at operation especially for ASD and TOF with no attendant link between distance to surgical centre and age at operation. In a study in among 460, 467 live births among Massachusetts residents between 2004 and 2009, Liberman, et al. [39], identified 916 CCHD cases, of which 126 (13.8\%) had delayed diagnosis. Rates of prenatal CCHD diagnosis increased from $44.9 \%$ in 2004 to $63.8 \%$ in 2009 , whereas rates of delayed diagnosis decreased from $17.1 \%$ to $10.6 \%$ over the same time period. They opined that delayed diagnosis was indeed associated with delivery outside a tertiary hospital.

\section{Conclusion}

Appropriate timing for cardiac surgery in children with congenital heart disease is very important as late surgical intervention could result in several morbidities and mortality. Literature search showed late timing of cardiac surgery in developing world especially in Africa. Factors such as late detection or diagnosis, poor counselling techniques used on our patients' parents especially in the area of follow up visits, poor health education to encourage parents/caregivers to present with their children early are all seen as associated factors been implicated in delayed timing of cardiac surgery especially in developed country.

\section{Recommendation}

Early detection or diagnosis (all hands must be on deck), proper counselling of our patients' parents especially in the area of follow up visits, more aggressive health education to encourage parents/caregivers to present with their children early are recommended. Preventive Cardiology through routine mass education and community cardiac outreaches with screening ECG and Echocardiography is also very advisable. Setting up well-structured foundation for indigent children with CHD and other cardiovascular diseases, training and re-training of medical staff and government providing an enabling environment for more corrective surgeries to be performed in our hospitals should be advocated.

\section{References}

1. Saxena A. Congenital cardiac surgery in the less privileged regions of the world. Expert Rev Cardiovasc Ther. 2009; 7: 1621-1629. PubMed: https://www.ncbi.nlm.nih.gov/pubmed/19954323

2. Tanner K, Sabrine N, Wren C. Cardiovascular malformations among preterm infants. Pediatrics. 2005; 116: e833-838.

PubMed: https://www.ncbi.nlm.nih.gov/pubmed/16322141

3. Marelli AJ, Mackie AS, lonescu-Ittu R, Rahme E, Pilote L. Congenital heart disease in the general population: changing prevalence and age distribution. Circulation. 2007; 115: 163-172.

PubMed: https://www.ncbi.nlm.nih.gov/pubmed/17210844

4. Tchervenkov $\mathrm{Cl}$, Jacobs JP, Bernier PL, Stellin G. The improvement of care for paediatric and congenital cardiac disease across the World: a challenge for the World Society for Pediatric and Congenital Heart Surgery. Cardiol Young. 2008; 18: 63-69.

PubMed: https://www.ncbi.nlm.nih.gov/pubmed/19063776

5. Rao PS. Pulmonary valve stenosis. In: Sievert $\mathrm{H}$, Qureshi SA, Wilson $\mathrm{N}$ Hijazi Z, eds. Percutaneous interventions in congenital heart disease. Oxford: Informa Health Care; 2007; 185-195.

6. Singh GK, Balfour IC, Chen S, et al. Lesion specific pressure recovery phenomenon in pediatric patients: a simultaneous Doppler and catheter correlative study. J Am Coll Cardiol. 2003; 41: 493.

7. Rao PS. Role of interventional cardiology in neonates: part II - Balloon angioplasty/valvuloplasty. Congenital Cardiol Today. 2008; 6: 1-14.

8. Roheena ZP, Awais A, Muhammad MA. Earlier surgical intervention in congenital heart disease results in better outcome and resource utilization. BMC Health Serv Res. 2011; 11: 353.

PubMed: https://www.ncbi.nlm.nih.gov/pmc/articles/PMC3277492/

9. Chang RK, Chen AY, Klitzner TS. Factors associated with age at operation for children with congenital heart disease. Pediatrics. 2000 105: 1073-1081.

PubMed: https://www.ncbi.nlm.nih.gov/pubmed/10790465

10. Liberman RF, Getz KD, Lin AE, Higgins CA, Sekhavat S, et al. Delayed diagnosis of critical congenital heart defects: trends and associated factors. Pediatrics. 2014; 134: 373-381.

PubMed: https://www.ncbi.nlm.nih.gov/pubmed/25070301

11. Roheena ZP, Awais A, Muhammad MA. Earlier surgical intervention in congenital heart disease results in better outcome and resource utilization. BMC Health Serv Res. 2011; 11: 353.

PubMed: https://www.ncbi.nlm.nih.gov/pmc/articles/PMC3277492/

12. Tariq W, Muhammad UR, Muhammad S. Surgical repair of partial atrioventricular septal defect. Pak J Med Sci. 2017; 33: 285-289. PubMed: https://www.ncbi.nlm.nih.gov/pmc/articles/PMC5432690/

13. Backer CL. Constantine Mavroudis. Atrioventricular Canal Defects, "Pediatric Cardiac Surgery" (4rth Edition), Carl L. Backer and Constantine Mavroudis. West Sussex: Wiley-Blackwell; 2013; 342-358.

14. Jacobs JP, Elloit MJ. In. Atrioventricular Canal Defects "Mastery of Cardiothoracic Surgery". 3rd Edition. Larry R Kaiser, Irving L Kron, Thomas L Spray., editors. Philadelphia: Wolters Kluwer/Lippincott Williams. 2014; 892-909.

15. Nicholas TK, Eugene HB, Frank LH, Kirklin JK. Atrioventricular Septal Defect, "Kirklin/Barratt-Boyes Cardiac Surgery”. Colleen Koch, Chandra Ramamoorthy. 4th edition. Philadelphia: Elsevier 2013; 1228-1273.

16. Rao PS, Harris AD. Recent advances in managing septal defects: ventricular septal defects and atrioventricular septal defects. F1000Res. 2018; 7: F1000.

PubMed: https://www.ncbi.nlm.nih.gov/pubmed/29770201

17. Rao PS. Diagnosis and management of acyanotic heart disease: part II -- left-to-right shunt lesions. Indian J Pediatr. 2005; 72: 503-512. PubMed: https://www.ncbi.nlm.nih.gov/ pubmed/15985740 
18. Kowalsky RH, Newburger JW, Rand WM, Castaneda AR. Factors determining access to surgery for children with congenital cardiac disease in Guatemala,Central America. Cardiol Young. 2006;16:385-391. PubMed: https://www.ncbi.nlm.nih.gov/pubmed/16839431

19. Tynan M, Anderson RH. Ventricular Septal Defect. Paediatric Cardiology, 2nd ed. Edinburgh, Scotland: Churchill Livingstone. 2002; 983-1014.

20. RaoPS. Consensusontiming ofinterventionforcommoncongenitalheart diseases:partl-acyanoticheart defects. Indian JPediatr. 2013;80:32-38. PubMed: https://www.ncbi.nlm.nih.gov/pubmed/22752706

21. Chelo D, Nguefack F, Menanga AP, Ngo Um S, Gody JC, et al. Spectrum of heart diseases in children: an echocardiographic study of 1,666 subjects in a pediatric hospital, Yaounde, Cameroon. Cardiovasc Diagn Ther. 2016; 6: 10-19.

PubMed: https://www.ncbi.nlm.nih.gov/pubmed/26885487

22. Nadas AS, Thilenius OG, Lafarge CG, Hauck AJ. Ventricular Septal Defect with Aortic Regurgitation: Medical and Pathologic Aspects. Circulation. 1964; 29: 862-873.

PubMed: https://www.ncbi.nlm.nih.gov/pubmed/14172095

23. Rao PS. Congenital heart defects-A review. In. Rao PS, ed. Congenital Heart Disease - Selected Aspects. In Tech, ISBN 978-953-307-472-6, Rijeka, Croatia, 2011; 3-44.

24. Mustafa KA, Tolga D, Cem C, Cenap Z. Bedside PDA ligation in premature infants less than 28 weeks and 1000 grams. J Cardiothorac Surg. 2016; 11: 146

PubMed: https://www.ncbi.nlm.nih.gov/pubmed/27716331

25. Lee LC, Tillett A, Tulloh R, Yates R, Kelsall W. Outcome following patent ductus arteriosus ligation in premature infants: a retrospective cohort analysis. BMC Pediatr. 2006; 6: 15. PubMed: https://www.ncbi.nlm. nih.gov/pubmed/16689986

26. El-Khuffash A, Weisz DE, McNamara PJ. Reflections of the changes in patent ductus arteriosus management during the last 10 years. Arch Dis Child Fetal Neonatal Ed. 2016; 101: F474-F478.

PubMed: https://www.ncbi.nlm.nih.gov/pubmed/27118761

27. Gillam-Krakauer M, Cotton RB, Reese J. Patent ductus arteriosus. In Feld LG, Mahan JD, Lorenz JM, Seigel WM, eds. Succinct Pediatrics: Evaluation and Management for Newborn, Genetic, Neurologic, and Developmental-Behavioral Disorders. Elk Grove Village, IL: American Academy of Pediatrics. 2017: 137-150.

28. HerrmanK,BoseC,LewisK,LaughonM.Spontaneousclosureofthepatent ductus arteriosus in very low birth weight infants following discharge from the neonatal unit. Arch Dis Child Fetal Neonatal Ed. 2009; 94: 48-50. PubMed: https://www.ncbi.nlm.nih.gov/pubmed/18450808

29. Weber SC, Weiss K, Bührer C, Hansmann G, Koehne P, et al. Natural history of patent ductus arteriosus in very low birth weight infants after discharge. J Pediatr. 2015; 167: 1149-1151.

PubMed: https://www.ncbi.nlm.nih.gov/pubmed/26239928

30. Oliver JM, Gallego P, Gonzalez AE, Sanchez-Recalde A, Bret M, et al. Pulmonary hypertension in young adults with repaired coarctation of the aorta: an unrecognised factor associated with premature mortality and heart failure. Int J Cardiol. 2014; 174: 324-329. PubMed: https://www.ncbi.nlm.nih.gov/pubmed/24768463

31. Rao PS. Diagnosis and management of acyanotic heart disease: Part II-Left-to-right shunt lesions. Indian J Pediatr. 2005: 72: 503-512. PubMed: https://www.ncbi.nlm.nih.gov/pubmed/15985740

32. Rao PS. Coarctation of the aorta. Curr Cardiol Rep. 2005; 7: 425-434 PubMed: https://www.ncbi.nlm.nih.gov/pubmed/16256011

33. Rao PS. Pulmonary valve disease. In Valvular Heart Disease. 3rd ed Alpert JS, Dalen JE, Rahimtoola S. Eds. Lippincott Raven: Philadelphia, PA, USA, 2000; 339-376.

34. Rachel DT, Michael JC, Gregory AF, Kevin DH. Coarctation of the aorta: Managementfrominfancytoadulthood.World JCardiol.2015;7:765-775. PubMed: https://www.ncbi.nlm.nih.gov/pubmed/26635924

35. Nugent EW, Freedom RM, Nora JJ, Ellison RC, Rowe RD, et al. Clinical course of pulmonic stenosis. Circulation 1977; 56: I38-47. PubMed: https://www.ncbi.nlm.nih.gov/pubmed/872344

36. Rao PS. Pulmonary valve disease. In Valvular Heart Disease, 3rd ed Alpert JS, Dalen JE, Rahimtoola S, Eds. Lippincott Raven: Philadelphia, PA, USA, 2000; 339

37. Marco P, Trivedi DB, Denise K, Robert AA. Tetralogy of Fallot: what operation, at which age European Journal of Cardio-Thoracic Surgery 2000; 6: 631-636.

38. Allen HD, Clark EB, Gutgessell HP, et al. editor. Moss and Adam's Heart Disease in Infants, Children and Adolescents. Philadelphia: Lippincott Williams and Wilkins. 2001: 880-902

39. Perry LW, Neill CA, Ferencz C, EUROCAT Working Party on. Congenital Heart Disease. Perspective in Pediatric Cardiology Epidemiology of congenital heart disease, the Baltimore-Washington Infant Study 1981 89. Armonk, NY: Futura; 1993; 33-62

40. Paula M, Eduardo C. Transposition of the great arteries. Orphanet $J$ Rare Dis. 2008; $3: 27$

PubMed: https://www.ncbi.nlm.nih.gov/pubmed/18851735

41. Duncan BW, Poirier NC, Mee RB, Drummond-Webb JJ, Qureshi A, et al. Selective timing for the arterial switch operation. Ann Thorac Surg. 2004; 77: 1691-1696.

PubMed: https://www.ncbi.nlm.nih.gov/pubmed/15111168 